INDONESIAN HEALTH ISSUE

\title{
Hubungan Usia Ibu Saat Hamil dengan Kejadian Stunting Pada Balita di Kabupaten Tangerang
}

\author{
Rangga Pusmaika ${ }^{1}$, Yizri Novfrida ${ }^{2}$, Erna Juliana Simatupang ${ }^{3}$, Moudy E.U \\ Djami ${ }^{4}$, lis Sumiyati ${ }^{5}$ \\ ${ }^{1-5}$ Akademi Kebidanan Bina Husada Tangerang \\ Email korespondensi: ranggapusmaika@gmail.com \\ No HP: 089636823238
}

\begin{abstract}
ARTICLE INFO
Received :

12 Januari 2022

Accepted :

14 Februari 2022

Published :

16 Februari 2022
\end{abstract}

Kata Kunci:

Stunting; Usia ibu

\section{Keywords:}

Stunting; Maternal Age

\begin{abstract}
ABSTRAK
Latar Belakang: Kondisi stunting pada masa depan mempengaruhi kualitas sumber daya manusia, yang akan berpengaruh pada Indeks Pembangunan Manusia (IPM). Usia Ibu saat hamil menjadi salah satu faktor risiko penyebab stunting pada anak. Stunting diakibatkan masalah gizi kompleks pada balita yang terjadi sejak kehamilan, salah satunya adalah kehamilan diusia remaja ataupun terlalu tua. Tujuan: untuk mengetahui hubungan usia ibu saat hamil dengan kejadian stunting di Kabupaten Tangerang.. Metode: Desain penelitian ini yaitu cross sectional dengan populasi adalah seluruh balita usia 0-5 tahun di desa Taban, Jambe, Tangerang dengan besar sampel 72 responden, diperoleh dengan teknik sytematic random sampling. Analisa Data menggunakan analisis univariat dan bivariat dengan uji chi-square. Hasil: Usia ibu saat hamil berhubungan dengan kejadian stunting $(p=0,036)$. Kesimpulan: Pentingnya pemberian informasi mengenai stunting kepada masyarakat terutama pasangan yang merencanakan kehamilan untuk mempersiapakan fisik dan psikis sejak awal kehamilan dan meningkatkan pengetahuan pemberian nutrisi pada anak.

ABSTRACT
Background: Stunting conditions in the future affect the quality of human
resources, which will affect the Human Development Index (HDI).
Maternal age during pregnancy is one of the risk factors for stunting in
children. Stunting is caused by complex nutritional problems in toddlers
that have occurred since pregnancy, one of which is pregnancy at the
age of teenagers or too old. Purpose: to determine the relationship
between maternal age during pregnancy and the incidence of stunting in
Tangerang Regency. Method: The design used a cross sectional design.
The study population was all toddlers aged 0-5 years in Taban village,
Jambe, Tangerang with a sample size of 72 respondents, obtained by
systematic random sampling technique. Data analysis used univariate
and bivariate analysis with chi-square test. Results: The results of the
study obtained that maternal age during pregnancy was associated with
the incidence of stunting (p = 0.036). Conclusion: The importance of
providing information about stunting to the public, especially couples
planning a pregnancy to be able to prepare physically and psychologically
from the beginning of pregnancy and increase knowledge of nutrition for
children.
\end{abstract}

(C) 2021 by the authors. Submitted for possible open access publication under the terms and conditions of the Creative Commons Attribution (CC BY SA) license (https://creativecommons.org/licenses/by-sa/4.0/). 


\section{PENDAHULUAN}

Pemenuhan kebutuhan nutrisi yang baik sangat penting untuk memastikan perkembangan fisik dan mental anak menjadi optimal dalam daur kehidupannya. Kondisi gizi kurang menyumbang 35\% dari kematian pada balita. Lebih dari 2 juta anak balita meninggal setiap tahun karena kekurangan gizi. Salah satu kondisi anak balita kekurangan gizi adalah stunting, yang mengacu pada kekurangan salah satu atau lebih nutrisi penting (Fikadu, Assegid and Amente, 2014) .

Pada tahun 2017, diperkirakan lebih dari setengah balita yang mengalami stunting di dunia berasal dari Asia (55\%), lebih dari sepertiganya (39\%) tinggal di Afrika. Data prevalensi balita stunting yang dikumpulkan World Health Organization (WHO), Indonesia termasuk ke dalam negara ketiga dengan prevalensi tertinggi di regional Asia Tenggara/South-East Asia Regional (SEAR) (Kemenkes RI, 2018). Di Indonesia satu dari tiga anak dibawah usia 5 tahun mengalami stunting (Bappenas and Unicef, 2017). Indonesia mengalami prevalensi stunting lebih besar dari prevalensi global dan Asia Tenggara yaitu sebesar 36,4\% (2019) . ditemukan balita sangat pendek dan pendek dengan prevalensi tinggi $(30 \%-<40 \%)$ di 18 provinsi (Kementerian Kesehatan RI, 2018).

Prevalensi stunting di Provinsi Banten tahun 2019, sebesar 24,11\% masih melewati batas prevalensi yang disarankan WHO (20\%). Dari 8 kabupaten/kota yang berada di Provinsi Banten prevalensi terbesar stunting adalah Kabupaten Pandeglang $(34,01 \%)$ disusul Kabupaten Lebak (32,96\%), sedangkan Kabupaten Tangerang sebesar 18,42\% (Kementerian Kesehatan RI, 2019). Kabupaten Tangerang dengan prevalensi kejadian stunting 18,42\%, lebih tinggi dibandingkan Kota Tangerang $(15,96 \%)$ dan Kota Tangerang Selatan $(15,39 \%)$ (Kesehatan, 2017). Pemerintah melakukan berbagai upaya untuk menurunkan angka stunting dan mengatasi stunting, dengan menjamin ketersediaan pangan yang meliputi gizi yang cukup, diharapkan dapat menurunkan prevalensi kekurangan gizi pada kantong-kantong stunting di wilayah Indonesia (Mohammad Teja, 2019) . Dalam upaya penurunan angka kekurangan gizi, baik stunting maupun wasting, sebagaimana yang tercantum dalam RPJMN 2020-2024, strategi nasional dalam percepatan penurunan stunting adalah pelayanan gizi di dalam dan di luar gedung, meliputi pelayanan promotif, preventif, kuratif, dan rehabilitatif dan target intervensi pada kelompok 1000 Hari Pertama Kehidupan (HPK) yaitu ibu hamil, ibu menyusui, bayi 0-23 bulan, balita dan remaja (Candarmaweni and Yayuk Sri Rahayu, 2020)

Berbagai faktor risiko terjadinya stunting di Indonesia dapat berasal dari faktor ibu, anak, maupun lingkungan. Usia lbu saat hamil menjadi salah satu fakrtor risiko penyebab stunting pada anak. Stunting diakibatkan masalah gizi kompleks pada balita yang terjadi sejak kehamilan, salah satunya adalah kehamilan remaja dimana kematangan fisik dan psikis mempengaruhi pertumbuhan anak yaitu stunting (Puspitasari, 2020). Penelitian Larasati (2018), diperoleh bahwa terdapat hubungan signifikan antara kehamilan remaja dengan kejadian stunting pada balita $(p=0,016)$. Semakin muda usia ibu mengalami kehamilan akan semakin besar risiko anak. Penelitian lainnya hubungan usia ibu saat hamil dengan stunted pada balita (Fitriahadi, 2018; Sani, 2019).

Berbagai dampak yang sangat merugikan dialami anak stunting dimasa depannya yang akan datang, Pendek (stunting) merupakan tragedi tersembunyi, kerusakan yang terjadi mengakibatkan perkembangan anak yang irreversible (tidak 
bisa diubah), anak tersebut tidak akan pernah mempelajari atau mendapatkan sebanyak yang dia bisa (Trihono et al., 2015). Mengingat masalah stunting merupakan perioritas program pemerintah dan merupakan masalah yang belum teratasi sampai saat ini, Kabupaten Tangerang oleh karenanya penting dilakukan penelitian terkait dengan stunting. Adapun tujuan penelitian ini untuk mengetahui hubungan usia ibu saat hamil dengan kejadian stunting di Desa Taban, Jambe, Tigaraksa Tangerang Tahun 2021.

\section{METODE PENELITIAN}

Jenis penelitian ini merupakan penelitian analitik menggunakan desain cross sectional. Penelitian ini dilakukan di Desa Taba, Jambe, Tigaraksa,, Kabupaten Tangerang tahun 2021. Populasinya adalah balita (usia 0-5 tahun) dengan sampel menggunakan rumusan besaran sampel didapatkan 36 balita tidak stunting dan 36 balita stunting. Teknik pengambilan sampel pada penelitian ini menggunakan tehnik systematic random sampling.

Variabel independent yang diteliti usia ibu saat hamil dan variabel dependen yaitu kejadian stunting. Pengumpulan data menggunakan data primer menggunakan lembar checklist meliputi data Tinggi badan/Panjang badan anak, berat badan anak, usia ibu saat hamil. Analisa Data menggunakan univariat dan bivariat dengan uji chi square.

\section{HASIL PENELITIAN}

Tabel 1 Distribusi Frekuensi Jenis Kelamin Balita

\begin{tabular}{c|c|c}
\hline Variabel & Frekuensi & $\%$ \\
\hline Laki-laki & 39 & 54,2 \\
\hline Perempuan & 33 & 45,8 \\
\hline Jumlah & 72 & 100 \\
\hline
\end{tabular}

Tabel 2 Distribusi Frekuensi Usia Ibu Saat Hamil

\begin{tabular}{c|c|c}
\hline Variabel & Frekuensi & \% \\
\hline Berisiko & 34 & 47,2 \\
\hline Tidak berisiko & 38 & 52,8 \\
\hline Jumlah & 72 & 100 \\
\hline
\end{tabular}

Berdasarkan tabel 1 dan 2 diperoleh bahwa lebih banyak balita dengan kelompok berjenis kelamin laki-laki $(54,2 \%)$, dan terdapat lebih banyak usia ibu saat hamil dalam kelompok tidak berisiko $(52,8 \%)$. 
Tabel 3 Hubungan Usia Ibu Saat Hamil dengan Kejadian Stunting

\begin{tabular}{|c|c|c|c|c|c|c|c|}
\hline \multirow{3}{*}{ Usia Ibu Saat Hamil } & \multicolumn{4}{|c|}{ Kejadian Stunting } & \multicolumn{2}{|c|}{ Total } & \multirow[t]{3}{*}{ P. Value } \\
\hline & \multicolumn{2}{|c|}{ Stunting } & \multicolumn{2}{|c|}{$\begin{array}{c}\text { Tidak } \\
\text { Stunting }\end{array}$} & & & \\
\hline & $f$ & $\%$ & $f$ & $\%$ & $f$ & $\%$ & \\
\hline Berisiko & 21 & 61,76 & 13 & 38,24 & 34 & 100 & 0,035 \\
\hline Tidak Berisiko & 14 & 36,84 & 24 & 63,16 & 38 & 100 & \\
\hline
\end{tabular}

Berdasarkan tabel 3 didapatkan hasil bahwa usia ibu saat hamil ( $p$-value 0,035 ) berhubungan kejadian stunting. Dari hasil penelitian juga diperoleh bahwa mayoritas ibu hamil diusia berisiko memiliki anak stunting $(61,76 \%)$ dan ibu hamil diusia yang tidak berisiko mayoritas memili anak yang tidak stunting $(63,16 \%)$.

\section{PEMBAHASAN}

Uji statistik menunjukkan terdapat hubungan antara usia ibu saat hamil dengan kejadian stunting di desa Taban, Jambe, Tigaraksa Tangerang ( $p$-value 0,035). Usia dikelompokkan menjadi usia berisiko ( $<20$ tahun dan $>35$ tahun dan usia tidak berisiko/ideal yaitu 20-35 tahun).

Hal ini sejalan dengan penelitian yang telah dilakukan sebelumnya pada anak balita di 31 Posyandu di Lombok Timur, Nusa Tenggara Barat, bahwa risiko stunting meningkat pada usia ibu saat hamil $<20$ tahun atau $>35$ tahun $(b=2.73 ; 95 \% \mathrm{Cl}=$ 0.38 to $5.42 ; p=0.047$ ) Anak dari ibu usia kehamilan 35 tahun memiliki risiko stunting sebesar 2,73 kali dibandingkan anak dari ibu usia kehamilan 20-35 tahun (Sajalia et al., 2018). Hal ini mungkin karena Wanita yang hamil di usia $<20$ tahun belum memiliki pengalaman dan pengetahuan tentang pemberian nutrisi pada anak. Pada usia < 20tahun, organ-organ reproduksi belum berfungsi sempurna dan >35 tahun terjadi penurunan reproduktif (Fajrina and Utami, 2016; Sajalia et al., 2018)

Penelitian lainnya di Lombok Barat tahun 2016, menunjukkan hubungan yang bermakna baik secara praktis maupun secara statistik antara kehamilan usia remaja dengan kejadian stunting. Kehamilan pada usia remaja kemungkinan 2,9 kali lebih banyak pada anak stunting (Irwansyah, Ismail and Hakimi, no date). Penelitian lainnya di Gianyar, Bali (2018) menunjukkan adanya hubungan signifikan antara usia berisiko pada ibu ( $<20$ tahun atau $>35$ tahun) dengan kejadian stunting.(Pratiwi and Wahyuningsih, 2018)

Berdasarkan penelitian di Bangladesh menggunakan data 30.000 ibu tahun 1996-2014, anak-anak yang lahir dari ibu remaja memiliki skor-z yang lebih rendah untuk tinggi badan menurut umur (perbedaan rata-rata: 0,64 SD), berat badan menurut umur ( $0.45 \mathrm{SD}$ ), dan prevalensi stunting yang lebih tinggi (18 poin persentase [pp]) dan berat badan kurang (12pp) dibandingkan anak-anak yang lahir 
dari ibu dewasa (Nguyen et al., 2020).

Proses kehamilan dipengaruhi oleh usia ibu saat hamil. Usia hamil lebih muda atau lebih tua akan berisiko mengalami komplikasi kehamilan. Kurangnya asuhan yang diperoleh ibu karena kehamilan remaja diprediksi menyebabkan BBLR serta kematian bayi. Sebagian besar remaja putri yang hamil dengan Indeks Masa Tubuh (IMT) kurang dari normal (underweight) memiliki risiko untuk melahirkan bayi dengan BBLR. Kurangnya asupan gizi karena kekhawatiran pada bentuk tubuh selama masa remaja dan kurangnya pendidikan tentang gizi dicurigai sebagai faktor kurangnya IMT pada kehamilan remaja. Kedua hal tersebut mengakibatkan rendahnya kenaikan BB ibu selama masa kehamilan yang berakibat pada kenaikan jumlah bayi lahir prematur (Vivatkusol, Thavaramara and Phaloprakarn, 2017).

Usia ibu mempunyai hubungan erat dengan berat bayi lahir, pada usia ibu yang masih muda $<20$ tahun, perkembangan organ-organ reproduksi dan fungsi fisiologisnya belum optimal. Selain itu emosi dan kejiwaannya belum cukup matang, sehingga pada saat kehamilan ibu tersebut belum dapat menghadapi kehamilannya secara sempurna, dan sering terjadi komplikasi-komplikasi. Risiko kehamilan akan terjadi pada ibu yang melahirkan dengan usia kurang dari 20 tahun dan lebih dari 35 tahun erat kaitannya dengan terjadinya preeclampsia, pertumbuhan janin yang buruk. Ini menunjukkan bahwa usia ibu pada kehamilan dapat mengakibatkan hasil kelahiran yang buruk yang menghambat pertumbuhan potensial anak (Sari and Sartika, 2021).

Berdasarkan penelitian di Ghana, Ibu usia remaja kurang memiliki kemampuan untuk menjamin asupan makanan yang memadai pada anak, akses ke air yang aman, dan kondisi sanitasi mengingat semua masalah yang terkait dengan melahirkan anak diusia remaja. Persaingan nutrisinya terjadi antara kebutuhan perkembangan pertumbuhan ibu dengan janin, ketidaksiapan secara psikologis untuk menyusui atau mungkin tidak memiliki sumber keuangan yang memadai untuk memenuhi kebutuhan bayi karena keadaan sosial ekonomi yang buruk. Ibu remaja mungkin tidak diterima oleh orang tua mereka, pasangan mereka mungkin juga remaja tanpa sumber pendapatan yang stabil, mereka mungkin mungkin mengalami tekanan pribadi karena hamil sebelum waktunya dan putus sekolah. Sebagai akibat dari masalah ini jumlah dan kualitas perawatan, perawatan dan pengasuhan yang mereka berikan kepada anak-anak mereka mungkin lebih sedikit dibandingkan dengan anak-anak dari ibu yang lebih dewasa. Hal ini kemungkinan akan mempengaruhi pertumbuhan dan perkembangan anak-anak mereka yang mengakibatkan kekurangan gizi dan defisit pertumbuhan lainnya(Wemakor et al., 2018).

Status gizi anak dipengaruhi usia ibu. Usia yang muda meningkatkan risiko melahirkan premature, keterlambatan pertumbuhan dalam rahim, kematian ibu dan janin juga kekurangan gizi. Ibu yang masih mudah juga umumnya memiliki status gizi yang kurang dibanding usia ibu ideal (20-35 tahun). Ibu yang hamil diusia yang terlalu tua juga memiliki kehamilan risiko tinggi diantaranya persalinan premature/BBLR, kelainan kromosom dan keterlambatan pertumbuhan dalam rahim (Rasmussen and Yaktine, 2009; Fall et al., 2015; Dewey, 2016). BBLR yaitu berat bayi lahir kurang dari 2.500 gram akan membawa risiko kematian, gangguan pertumbuhan dan perkembangan anak, termasuk dapat berisiko menjadi pendek jika tidak tertangani dengan baik (Kemenkes RI, 2016).

Ibu yang pertama kali hamil diusia $\geq 25$ tahun memiliki efek perlindungan yang signifikan terhadap peluang seorang bayi baru lahir mengalami stunting. Studi terhadap 55 negara menunjukkan bahwa meningkatkan usia pada kehamilan 
pertama menjadi 27-29 dapat menurunkan angka kematian bayi dan hasil kesehatan anak yang merugikan (Stunting, kurus, anemia, diare). lbu yang kehamilan pertamanya berada dalam kisaran usia 27-29 (kelahiran pertama tertunda) lebih cenderung hidup dalam kondisi sanitasi yang lebih baik, memiliki tingkat pendidikan tinggi, memiliki status sosial ekonomi yang lebih tinggi, memiliki pasangan, dan tinggal di daerah perkotaan (Sari and Sartika, 2021).

Terdapat keterbatasan pada penelitian ini dimana banyak sekali faktor yang berhubungan dengan stunting sehingga usia saat hamil bukanlah mutlak menjadi kemungkinan penyebab dari kejadian stunting.

\section{SIMPULAN DAN SARAN}

\section{SIMPULAN}

Pada Penelitian ini diperoleh hasil bahwa terdapat hubungan antar usia ibu saat hamil dengan kejadian stunting. Ibu dengan usia berisiko mayoritas memiliki anak stunting dan ibu dengan kelompok tidak berisiko mayoritas memiliki anak tidak stunting.

\section{SARAN}

Adapun saran yang diberikan yaitu pentingnya pemberian informasi mengenai stunting kepada masyarakat terutama pasangan yang merencanakan kehamilan untuk dapat mempersiapakn fisik dan psikis sejak awal kehamilan dan meningkatkan pengetahuan pemberian nutrisi pada anak.

\section{DAFTAR PUSTAKA}

Bappenas and Unicef (2017) 'Laporan Baseline SDG tentang Anak-Anak di Indonesia', Kementerian Perencanaan Pembangunan Nasional (Bappenas) dan United Nations Children's Fund, pp. 1-105.

Candarmaweni and Yayuk Sri Rahayu, A. (2020) 'Tantangan Pencegahan Stunting Pada Era Adaptasi Baru "New Normal" Melalui Pemberdayaan Masyarakat Di Kabupaten Pandeglang the Challenges of Preventing Stunting in Indonesia in the New Normal Era Through Community Engagement', Jurnal Kebijakan Kesehatan Indonesia: JKKI, 9(3), pp. 136-146.

Dewey, K. G. (2016) 'Reducing stunting by improving maternal, infant and young child nutrition in regions such as South Asia: evidence, challenges and opportunities.', Maternal \& child nutrition, 12 Suppl 1(Suppl 1), pp. 27-38. doi: 10.1111/mcn.12282.

Fajrina, N. and Utami, F. S. (2016) 'Hubungan Faktor Ibu dengan Kejadian Stunting pada Balita di Puskesmas Piyungan Kabupaten Bantul'. Universitas' Aisyiyah Yogyakarta.

Fall, C. H. D. et al. (2015) 'Association between maternal age at childbirth and child and adult outcomes in the offspring: a prospective study in five low-income and middle-income countries (COHORTS collaboration).', The Lancet. Global health, 
3(7), pp. e366-77. doi: 10.1016/S2214-109X(15)00038-8.

Fikadu, T., Assegid, S. and Amente, L. D. (2014) 'Factors Associated with Stunting Among Children of Age 24 to 59 Months in Meskan District, Gurage Zone, South Ethiopia: a Case-Control Study', BMC Public Health, 14(800), pp. 1-7. doi: 10.1186/1471-2458-14-800.

Fitriahadi, E. (2018) 'Hubungan tinggi badan ibu dengan kejadian stunting pada balita usia 24 -59 bulan', Jurnal Kebidanan dan Keperawatan Aisyiyah, 14(1), pp. 15-24. doi: 10.31101/jkk.545.

Irwansyah, I., Ismail, D. and Hakimi, M. (no date) 'Kehamilan remaja dan kejadian stunting anak usia $6-23$ bulan di Lombok Barat'.

Kemenkes RI (2016) 'Situasi Balita Pendek', Kementerian Kesehatan Republik Indonesia, ISSN 2442-(Hari anak Balita 8 April), pp. 1-10.

Kemenkes RI (2018) Situasi Balita Pendek (Stunting) di Indonesia, Kementerian Kesehatan RI.

Kementerian Kesehatan RI (2018) Laporan Nasional Riskesdas 2018. Jakarta: Badan Penelitian dan Pengembangan Kesehatan.

Kementerian Kesehatan RI (2019) Laporan Pelaksanaan Integrasi Susenas Maret 2019 dan SSGBI Tahun 2019. Jakarta.

Kesehatan, D. (2017) 'Profil Kesehatan Kabupaten Tanah Datar 2017’, (021), p. 144.

Mohammad Teja (2019) 'Stunting Balita Indonesia dan Penanggulangannya', IPusat Penelitian Badan Keahlian DPR RI.

Nguyen, P. et al. (2020) 'Why Are Adolescent Mothers More iikely to Have Stunted and Underweight Children Than Adult Mothers? A Path Analysis Using Data from 30,000 Bangladeshi Mothers, 1996-2014', Current Developments in Nutrition, 4(Supplement_2), p. 1463. doi: 10.1093/cdn/nzaa061_091.

Pratiwi, I. G. and Wahyuningsih, R. (2018) 'Risk Factors of Stunting Among Children in Some Areas in Indonesia: A Literature Review', International Journal of Studies in Nursing. July Press Pte. Ltd., 3(3), p. 41. doi: 10.20849/ijsn.v3i3.468.

Puspitasari, R. C. (2020) 'HUBUNGAN KEHAMILAN USIA REMAJA DENGAN KEJADIAN STUNTING PADA BALITA USIA 24-59 BULAN DI KABUPATEN KULON PROGO'. Poltekkes Kemenkes Yogyakarta.

Rasmussen, K. M. and Yaktine, A. L. (eds) (2009) No Title. Washington (DC). doi: $10.17226 / 12584$.

Sajalia, H. et al. (2018) 'Life Course Epidemiology on the Determinants of Stunting in Children Under Five in East Lombok, West Nusa Tenggara', 3, pp. 242-251.

Sani, M. (2019) Hubungan Usia Ibu saat Hamil dengan Stunted pada Balita 24-59 Bulan di Wilayah Kerja Puskesmas Citeras. 
Sari, K. and Sartika, R. A. D. (2021) 'The effect of the physical factors of parents and children on stunting at birth among newborns in indonesia', Journal of Preventive Medicine and Public Health, 54(5), pp. 309-316. doi: 10.3961/jpmph.21.120.

Trihono et al. (2015) Pendek (Stunting) di Indonesia, Masalah dan Solusinya. Badan Penelitian dan Pengembangan Kesehatan.

Vivatkusol, Y., Thavaramara, T. and Phaloprakarn, C. (2017) 'Inappropriate gestational weight gain among teenage pregnancies: Prevalence and pregnancy outcomes', International Journal of Women's Health, 9, pp. 347-352. doi: 10.2147/IJWH.S128941.

Wemakor, A. et al. (2018) 'Young maternal age is a risk factor for child undernutrition in Tamale Metropolis, Ghana', BMC research notes. BioMed Central, 11(1), p. 877. doi: 10.1186/s13104-018-3980-7.

(2019) 'WHO', p. 2019. 